\title{
Light Intensity and Spectral Quality Affect Fruit Growth and Shelf Life of Greenhouse-grown Long English Cucumber
}

\author{
W.C. Lin ${ }^{1}$ \\ Agriculture and Agri-Food Canada, Pacific Agriculture Research Centre, P.O.Box 1000, Agassiz, B.C. \\ VOM 1A0, Canada \\ P.A. Jolliffe \\ Department of Plant Science, University of British Columbia, Vancouver, B.C. V6T 1Z4, Canada
}

Additional index words. canopy light, fruit color, postharvest, Cucumis sativus

\begin{abstract}
The importance of light intensity and spectral quality on fruit color and shelf life of long English cucumber (Cucumis sativus L.) was studied in four greenhouse experiments. The intensity of cucumber greenness was measured nondestructively by video imaging, and shelf life was measured by visual observation of incipient yellowing. In the summer, filters were used to cover individual fruit to reduce light intensity reaching the fruit surface. The lower the light intensity incident on a cucumber, the shorter its shelf life. The average shelf life was 8,5, or 1 days for cucumbers receiving $100 \%, 66 \%$, or $31 \%$ of natural daylight, respectively. The fruit that were covered with a filter transmitting red (R) light were greener (low grey level via video imaging) than those with a far-red (FR) filter. In the fall, fruit receiving spectral $R$ lighting from fluorescence tubes were greener and had a longer shelf life than those receiving FR lighting from incandescent bulbs. In the winter, high-pressure sodium (HPS) lighting was necessary to supplement natural daylight for crop growth and production. Under HPS, $R$ and FR lighting produced the same fruit greenness and shelf life. In the spring, R-lighted fruit had longer shelf life than FR-lighted ones, although fruit color at harvest was similar. In these four experiments, postharvest shelf life of long English cucumber was generally related to fruit greenness upon harvest. The data suggest the importance of an open canopy in improving fruit greenness and shelf life of greenhouse-grown cucumbers.
\end{abstract}

The shelf life of greenhouse-grown long English cucumbers has, for all practical purposes, expired when incipient yellowing occurs (Lin, 1989). Preharvest conditions, such as location of fruit in the canopy, affect postharvest shelf life (Lin and Ehret, 1991). Cucumbers harvested from the upper canopy tend to have a longer shelf life than those from the lower canopy. Training methods that open the canopy improve shelf life (Klieber et al., 1993). These authors suggested that high light intensity reaching the fruit surface results in high chlorophyll content, and that high chlorophyll content at harvest is associated with long shelf life during storage. These conclusions were based on correlations between incident canopy light intensity and shelf life of greenhouse cucumbers involving fruit thinning and stem training (Klieber et al., 1993; Lin and Ehret, 1991). However, direct evidence for light intensity affecting cucumber shelf life is lacking.

In many plant species, chlorophyll formation increases under high light intensity (Bjorkman, 1981; Mclaren and Smith, 1978). Leaves in shade have lower chlorophyll content than unshaded ones (Barreiro et al., 1992). Low chlorophyll content is also associated with a low ratio of red (R) to far-red (FR) light (Miller and Zalik, 1965). Red light is associated with slow degradation of chlorophyll during senescence (Okada et al., 1992; Tucker, 1981). The role of spectral light quality in cucumber fruit color and shelf life has not been described in the literature.

\footnotetext{
Received for publication 4 Apr. 1996. Accepted for publication 21 June 1996 Contribution no. 549 of Agriculture and Agri-Food Canada, Pacific Agriculture Research Centre. The study was supported by a joint grant from Natural Sciences and Engineering Research Council of Canada, Agriculture Canada, and the British Columbia Greenhouse Vegetable Research Council. We thank John W. Hall for statistical analysis of data. Technical assistance of Glenn Block, Sabina Stan, and Elaine Taylor is acknowledged. The cost of publishing this paper was defrayed in part by the payment of page charges. Under postal regulations, this paper therefore must be hereby marked advertisement solely to indicate this fact.

${ }^{1}$ To whom reprint requests should be addressed.
}

Greenhouse cucumber production normally lasts 10 to 11 months (British Columbia Ministry of Agriculture and Fisheries, 1988). Therefore, crops are subjected to enormous variation in natural daylight. Additionally, canopy density also varies according to greenhouse management. The variation of light intensity and spectral quality throughout the production season is expected. At the beginning, each plant has one main stem producing fruit. After being topped, each plant is trained to have four to six laterals per plant. Eventually the canopy becomes very crowded. Inside the canopy, light intensity is expected to be low, and light quality shifted to low R/FR ratios (Holmes, 1983). In this study, greenhouse cucumbers were produced under reduced light intensity or subjected to altered spectral light quality using various color filters or spectral lighting to elucidate the effects of light intensity and spectral quality on fruit growth and postharvest shelf life.

\section{Materials and Methods}

Seeds of 'Mustang' long English cucumber (Cucumis sativus) were individually sown in rockwool cubes and transplanted into 28-L bags of sawdust (one plant per bag) at a density of 1.6 plants/ $\mathrm{m}^{2}$. The nutrient solution was based on the Nursery, Greenhouse Vegetables and Ornamental Production Guide for Commercial Growers (British Columbia Ministry of Agriculture and Fisheries, 1988). All plants were irrigated with the same frequency and duration (about $200 \mathrm{~mL} /$ plant every 1 to $2 \mathrm{~h}$ depending on prevailing light levels). The electrical conductivity and $\mathrm{pH}$ of the fertilizer solution were $1.8 \mathrm{mS} \cdot \mathrm{cm}^{-1}$ and 5.7 , respectively. Plants were trained according to an umbrella system as previously reported (Lin and Ehret, 1991).

The first of four experiments was conducted in the summer, when natural daylight was high enough to allow the use of filters around individual fruit to examine the effects of reduced light intensity and altered spectral quality reaching each cucumber fruit 
Table 1. The growing conditions of four greenhouse experiments in studying the effects of light intensity and spectral quality on fruit growth and shelf life of long English cucumbers.

\begin{tabular}{|c|c|c|c|c|c|c|c|}
\hline \multirow[b]{2}{*}{ Expt. } & \multirow[b]{2}{*}{ Treatment } & \multirow[b]{2}{*}{$\mathrm{HPS}^{\mathrm{z}}$} & \multirow[b]{2}{*}{ Seasons (duration) } & \multirow[b]{2}{*}{ PPFD $^{y}$} & \multicolumn{3}{|c|}{ Air temp $\left({ }^{\circ} \mathrm{C}\right)$} \\
\hline & & & & & Max & Min & Avg \\
\hline Summer & $\begin{array}{c}\text { Shading } \\
\text { Color filter }\end{array}$ & - & Summer (21 May-29 July) & 29.9 & 27.0 & 19.4 & 23.3 \\
\hline Fall & $\mathrm{R}, \mathrm{FR}$ lighting & - & Fall (29 Sept.-18 Nov.) & 8.9 & 24.8 & 19.4 & 21.6 \\
\hline Winter & $\mathrm{R}, \mathrm{FR}$ lighting & + & Winter (23 Nov.-26 Mar.) & 5.9 & 23.3 & 19.1 & 20.9 \\
\hline Spring & $\mathrm{R}, \mathrm{FR}$ lighting & - & Spring (26 Mar.-23 Apr.) & 21.4 & 26.1 & 19.8 & 22.6 \\
\hline
\end{tabular}

${ }^{\mathrm{z}}$ Supplementary lighting with high-pressure sodium (HPS) lamps.

${ }^{\mathrm{y}}$ Average photosynthetic photon flux density $\left(\mathrm{mol} \cdot \mathrm{m}^{-2} \cdot \mathrm{d}^{-1}\right)$ during the greenhouse experiment.

surface (Table 1). In the following production seasons, when the natural daylight was low, the use of filters became impossible due to the fact that they reduced the light reaching the fruit to unacceptable levels. Therefore, in three subsequent experiments, spectral R and FR lighting were applied to whole plants in addition to natural daylight.

\section{Summer filter experiment}

There were two subexperiments: shading (reduced light intensity) and color filters (altered light quality) (Table 1). In each subexperiment, there were two blocks with three treatments per block. There were four plants in each treatment. Each plant had one fruit on each of nodes 9, 11, 13 and 15 on the main stem. Each fruit was bagged on the day of anthesis (full open bloom) with a filter ( $47 \mathrm{~cm}$ long and $14 \mathrm{~cm}$ in circumference). The blossom end of the filter tube was open, and the tube was positioned so the filter had minimal contact with the fruit surface.

Shading. This subexperiment treatments consisted of 1) control with no filter, 2) two layers of Reemay textile fiber (E.I. Du Pont, Wilmington, Del.), and 3) one layer of Lee 270 screen (William F. White Ltd., North Vancouver, B.C., Canada). Light intensity reaching the fruit in the three treatments was $100 \%, 66 \%$, and $31 \%$ of natural daylight, respectively. The photosynthetic photon flux density (PPFD) passing through a filter was determined using a quantum sensor and meter ((LI-190SB and LI-198; LI-COR, Lincoln, Neb.).

Color filter. This subexperiment was conducted with Rasco filters (William F. White Ltd.) and consisted of 1) control using a Rasco 119 clear filter, 2) a R filter using Rasco 24 red plus Lee 270 neutral, and 3) a FR filter using Rasco 24 red plus Rasco 93 green. The light intensity reaching the fruit surface was $88 \%, 10 \%$, and $10 \%$ of daylight, respectively. The R/FR ratios in the light reaching the fruit were $1.0,1.4$, and 0.15 , respectively. The spectral quality of filtered light was measured by a spectroradiometer (LI-1800; LI-COR) and R/FR ratio was calculated by dividing transmitted light at 650 to $700 \mathrm{~nm}$ by that at 700 to $750 \mathrm{~nm}$.

All fruit were harvested 3 weeks after date of anthesis. Weight, length, and diameter of each fruit were measured on the date of harvest. Chlorophyll content was estimated by video imaging (Lin et al., 1993) and the average grey level (low grey level = dark green $=$ high chlorophyll content) of each fruit was recorded. Grey level was measured on a specific side on the day of harvest and on the same side every week during the subsequent 2 weeks in storage. Each fruit was individually placed in a perforated polyethylene tube $(48 \times 13 \mathrm{~cm})$ with one end unsealed. Fruit were stored at 13 ${ }^{\circ} \mathrm{C}$ and $90 \%$ to $95 \%$ relative humidity $(\mathrm{RH})$ for 2 weeks and visually observed every $2 \mathrm{~d}$ for incipient yellowing (initial sign of chlorophyll degradation). Shelf life was defined as days between harvest and occurrence of incipient yellowing.

\section{Fall spectral lighting}

There were two blocks (replicates) each consisting of three plots (treatments) (Table 1). Each plot was randomly assigned to one of three lighting treatments. Each lighting treatment consisted of eight plants being oriented in two north-south rows and the whole plot was partitioned by a 2.2-m-high curtain to exclude light coming from adjacent treatments. The experiment was conducted without HPS supplemental lighting. Daily $11 \mathrm{~h}$ of $\mathrm{R}$ and FR lighting (0730 to 1830 DST) began 20 Oct 1992, and was changed into daily $10 \mathrm{~h}$ (0700 to 1700 PST) on 5 Nov. Light spectra were measured with a portable spectroradiometer (LI-1800). Three scans were made between 330 and $800 \mathrm{~nm}$ with 2-nm intervals and then averaged. The $\mathrm{R} / \mathrm{FR}$ ratio was calculated by the ratio of ( 650 to $700 \mathrm{~nm}) /(700$ to $750 \mathrm{~nm})$. Red lighting was provided by $15-\mathrm{W}$ fluorescent tubes (Hitachi FL 15BR; Hitachi Ltd., Tokyo) with a $\mathrm{R} / \mathrm{FR}$ ratio of 11.5 . The FR lighting was provided by $60-\mathrm{W}$ frosted incandescent bulbs (GTE Sylvania Canada Ltd., Drummonville, Quebec, Canada) with a R/FR ratio of 0.7 . Three lamps were fastened to a vertical lighting post at 50,120, and $190 \mathrm{~cm}$ above ground, and they were arranged at 120 degrees rotation horizontally. One lighting post was used to light four adjacent plants, and another for the other four plants. There were six lamps on two posts for eight plants inside a curtain. In the greenhouse, the R/FR ratios of natural daylight, fluorescent, and incandescent treatments were $0.69,0.85$, and 0.50 , respectively. The intensity of spectral $R$ and FR lighting contributed $<5 \%$ of natural daylight in the control.

Flowers were individually tagged at anthesis on 21, 26, and 29 Oct. 1992. Fruit were checked three times a week and harvested when $27 \mathrm{~cm}$ long, or 4 weeks after anthesis at the latest. Weight, length, diameter, and chlorophyll content of each fruit were measured on the date of harvest. Each fruit was placed in a polyethylene tube and stored for 4 weeks under conditions as described in the first experiment. Chlorophyll content was estimated weekly during the 4 -week storage at $13{ }^{\circ} \mathrm{C}$, and shelf life was visually observed every 2 days as in the previous experiment.

\section{Winter spectral lighting plus HPS}

In winter experiment, supplementary HPS lighting was necessary for proper crop production. A greenhouse section was divided into two blocks (replicates) with three plots (treatments) each as described in the second experiment. Each treatment consisted of eight plants partitioned and lighted by one HPS lighting fixture (P.L. Light Systems, Canada). In all treatments, daily 11.5 h (0700 to 1830) high level (photosynthetic) HPS lighting began 16 Dec. 1992 until the end of the experiment. There were three treatments with the same photoperiod of $12 \mathrm{~h}$ (0700 to 1900): control, R, and FR lighting (Table 1). The control treatment was lighted with lowlevel (photoperiodic) HPS lighting, while R and FR lighting with fluorescent tubes or incandescent bulbs, respectively. There were 
two R or FR lighting fixtures per treatment plot of eight plants as described in the second experiment.

Each plant had an equal number of fruit. One fruit per nodes 9 to 19 of the main stem was used. Every other day, one fruit per plant was tagged on anthesis. The node positions were recorded. Plants were topped at $2.1 \mathrm{~m}$ high and allowed to have two laterals (allowing one fruit per node from node 3 to 12). One fruit on each node of 4,6 , and 8 was tagged on the same day. All fruit were harvested $21 \mathrm{~d}$ after anthesis. Weight, length, and diameter were determined on the day of harvest. Grey level and shelf life of each fruit were measured as described in the first experiment.

\section{Spring spectral lighting}

A greenhouse section was divided into two blocks (replicates) with three plots (treatments) each. Each treatment had eight plants and was isolated by a partition. No HPS supplemental lighting was used. There were three treatments: Control, R, and FR lighting (Table 1). In the control treatment, the natural daylight 0600 to 1900 was recorded on 23 Apr. In R (fluorescent light) and FR lighting (incandescent light), plants were lighted $11.0 \mathrm{~h}$ daily (0800 to 1900) with two R or two FR light fixtures per treatment plot of eight plants.

One fruit per node from 9 to 19 of the main stem was allowed. Every other day, one fruit per plant was tagged on anthesis. Three fruit per main stem were tagged for experimental purpose and their node positions were recorded. All fruit were harvested $14 \mathrm{~d}$ after anthesis. Weight and length of each cucumber were determined on the day of harvest. The average grey level of each fruit was measured weekly as described in the first experiment.

\section{Data analysis}

A randomized complete-block design was used in all four experiments. All data were averaged over all nodes constituting repeated measures. Analysis of variance was performed using a general linear model (SAS Institute, Cary, N.C.). In the first experiment (shading), the sum of squares was partitioned into linear and quadratic. For the color filter part of the first experiment and three subsequent spectral lighting experiments, sum of squares was partitioned into control vs. other (two lighting treatments), and $\mathrm{R}$ vs. FR lighting. Shelf life of an individual fruit was regressed on its image grey level.

\section{Results}

\section{Summer filter experiment}

Shading. High light intensity (i.e., control without a filter) resulted in larger cucumber fruit (length, diameter, and fresh weight), greener fruit (lower grey level) at harvest and after 2-week storage, and longer shelf life (Table 2) compared to lower intensities.

Color filter. Control fruit with a clear neutral filter had larger diameter than those with R or FR filters (Table 2). There was no difference between R- and FR-treated fruit in length, diameter, and weight. The control fruit had higher chlorophyll content (lower grey level) at harvest and a lower rate of chlorophyll degradation in 2-week storage than those covered with R or RF filters. Cucumbers with $\mathrm{R}$ and FR filters were yellowish green at harvest due to low light intensity (about 10\% PPFD) passing through these filters (Table 2). Fruit covered with R filters were greener (i.e., low grey level) at harvest than those with FR filters. The same trend persisted during 2-week storage. The control fruit had $7 \mathrm{~d}$ of shelf life, but fruit covered with R or FR filters were yellow at harvest and had no shelf life.

\section{Fall spectral lighting}

Control fruit had similar fruit growth as compared to R- and FRlighted ones (Table 3). Between lighting treatments, R-lighted fruit were shorter and thinner and weighed less than FR-lighted ones. Control fruit were less green than R- or FR-lighted ones at harvest and throughout 4-week storage (Table 3). R-lighted fruit were greener at harvest and after 3 weeks in storage than FRtreated fruit. R-lighted fruit had longer shelf lives than FR-lighted ones.

\section{Winter spectral lighting}

The control fruit were thicker than R- or FR-lighted fruit (Table

Table 2. The effects of shading and color filters on fruit growth, image grey level, and shelf life of greenhouse-grown cucumber.

\begin{tabular}{|c|c|c|c|c|c|c|c|c|}
\hline \multirow[b]{3}{*}{ Treatment } & \multicolumn{3}{|c|}{ Fruit growth } & \multirow{2}{*}{\multicolumn{3}{|c|}{$\begin{array}{c}\text { Grey level after storage } \\
\text { (weeks) }\end{array}$}} & \multirow{3}{*}{$\begin{array}{l}\text { Difference } \\
2 \text { weeks }\end{array}$} & \multirow{3}{*}{$\begin{array}{l}\text { Shelf life } \\
(d)^{y}\end{array}$} \\
\hline & \multirow{2}{*}{$\begin{array}{l}\text { Length } \\
(\mathrm{cm})\end{array}$} & \multirow{2}{*}{$\begin{array}{l}\text { Diam } \\
(\mathrm{cm})\end{array}$} & \multirow{2}{*}{$\begin{array}{l}\mathrm{Wt} \\
(\mathrm{g})\end{array}$} & & & & & \\
\hline & & & & 0 & 1 & 2 & & \\
\hline \multicolumn{9}{|c|}{ Summer shading (light intensity) } \\
\hline $100 \%$ & 34.3 & 5.13 & 503 & 92.8 & 94.3 & 95.9 & 3.1 & 8.4 \\
\hline $66 \%$ & 33.2 & 4.98 & 451 & 94.7 & 96.1 & 97.8 & 3.0 & 4.6 \\
\hline $31 \%$ & 32.4 & 4.48 & 411 & 102.3 & 103.8 & 105.3 & 2.9 & 0.7 \\
\hline \multicolumn{9}{|l|}{ Significance } \\
\hline Treatment & $* *$ & $* *$ & $* *$ & $* *$ & $* *$ & $* *$ & NS & $* *$ \\
\hline Linear & $* *$ & $* *$ & $* *$ & $* *$ & $* *$ & $* *$ & NS & $* *$ \\
\hline Quadratic & NS & NS & NS & $* *$ & $* *$ & $* *$ & NS & NS \\
\hline \multicolumn{9}{|c|}{ Summer color filter (light quality) } \\
\hline Control $(\mathrm{CK})$ & 36.8 & 5.87 & 503 & 92.2 & 94.2 & 95.7 & 3.5 & 7.3 \\
\hline $\mathrm{R}$ filter & 32.8 & 5.21 & 468 & 113.0 & 115.3 & 114.1 & 6.0 & 0 \\
\hline FR filter & 32.9 & 5.14 & 457 & 134.6 & 136.5 & 140.4 & 5.8 & 0 \\
\hline \multicolumn{9}{|c|}{ Single degree of freedom contrast } \\
\hline CK vs. other & NS & $*$ & NS & $* *$ & $* *$ & $* *$ & $* *$ & $* *$ \\
\hline R vs. FR & NS & NS & NS & $* *$ & $* *$ & $* *$ & NS & NS \\
\hline
\end{tabular}

${ }^{\mathrm{z}}$ Grey level measured by video imaging with a 550-nm filter $(0=$ absolute black; and $255=$ absolute white). Low grey level indicates dark green. ${ }^{y}$ Shelf life during storage at $13{ }^{\circ} \mathrm{C}$ for 2 weeks.

Ns,**** Nonsignificant or significant at $P=0.05$ or 0.01 , respectively. 
3). There was no difference between R- and FR-lighting in fruit length and weight, fruit color and shelf life.

\section{Spring spectral lighting}

The control fruit were shorter and weighed less than R- or FRlighted fruit (Table 3). There were no differences in fruit growth characteristics between R and FR lighting. Control fruit were not as green as R- or FR-lighted fruit at harvest, and remained less green toward the end of 3-week storage. There were no differences in greenness between R- and FR-lighted fruit. R-lighted fruit had a lower rate of chlorophyll degradation than FR- treated or control fruit during the third and fourth week in storage. Control fruit had a shorter shelf life than R- or FR-lighted fruit. R-lighted fruit had a longer shelf life than FR-lighted fruit.

\section{Discussion}

Postharvest shelf life of long English cucumber is terminated by the occurrence of incipient yellowing (Lin, 1989). Shelf life has been correlated with fruit green color at harvest (Lin and Ehret, 1991). Green color was the estimate of chlorophyll content in cucumber peel, and chlorophyll content can be determined by nondestructive video imaging (Lin et al., 1993). High chlorophyll content can be expressed by low grey level. Our previous study indicated that cucumber shelf life was correlated with fruit color and that fruit color was correlated with the amount of incident canopy light reaching the fruit surface (Klieber et al., 1993). The data obtained in the present experiments provide direct evidence to explain the roles of canopy light in postharvest shelf life of long English cucumber.

Light intensity. High light intensity resulted in high chlorophyll content (i.e., low grey level) at harvest as observed in the summer shading experiment where light intensity was reduced to different levels at the fruit surface (Table 2). This experiment provided the direct evidence that high light intensity is necessary for high chlorophyll content in cucumber. This experiment also confirmed our previous result that high chlorophyll content was positively correlated with a high percentage of PPFD reaching the fruit surface (Klieber et al., 1993). These results are similar to a previous report that chlorophyll content of barley seedlings increased as light intensity increased (Miller and Zalik, 1965). No effect of light intensity on the rate of chlorophyll degradation was observed in our experiment (Table 2), which confirmed our previous assumption that fruit color at harvest can be indicative of potential shelf life (Lin and Ehret, 1991). Therefore, the relationship between high light intensity and long shelf life in cucumber can be explained on the basis of high chlorophyll content in the peel.

Light quality. The effects of spectral light quality on cucumber chlorophyll formation and shelf life were first examined by using color filters and then by spectral lighting. First, in using color filters in the summer experiment, the light intensity passing through the filters was reduced to about $10 \%$ of natural daylight, and the cucumbers covered with color filters had no shelf life (Table 2). These R- and FR-filtered cucumbers showed lack of greenness even on the date of harvest, and they were not green enough to be considered marketable. The cucumber fruit covered with a $\mathrm{R}$ filter had higher chlorophyll content than those with FR filters. Considering the fact that these color filters reduced the light so much, three subsequent spectral lighting experiments were conducted with spectral lighting in addition to natural daylight. The benefit of $\mathrm{R}$ lighting to long shelf life was observed in two of three lighting experiments. In fall spectral lighting experiment, Rlighted fruit were greener and had longer shelf lives than FRlighted ones (Table 3). These observations are similar to previous

Table 3. The effect of spectral lighting on fruit growth, image grey levels, and shelf life of greenhouse grown cucumber.

\begin{tabular}{|c|c|c|c|c|c|c|c|c|c|c|}
\hline \multirow[b]{3}{*}{ Treatment } & \multicolumn{3}{|c|}{ Fruit growth } & \multirow{2}{*}{\multicolumn{5}{|c|}{$\begin{array}{l}\text { Grey level after storage }{ }^{z} \\
\text { (weeks) }\end{array}$}} & \multirow{3}{*}{$\begin{array}{l}\text { Difference } \\
4 \text { weeks }\end{array}$} & \multirow{3}{*}{$\begin{array}{l}\text { Shelf life }{ }^{y} \\
\text { (d) }\end{array}$} \\
\hline & \multirow{2}{*}{$\begin{array}{l}\text { Length } \\
(\mathrm{cm})\end{array}$} & \multirow{2}{*}{$\begin{array}{l}\text { Diam } \\
(\mathrm{cm})\end{array}$} & \multirow{2}{*}{$\begin{array}{l}\text { Wt } \\
(\mathrm{g})\end{array}$} & & & & & & & \\
\hline & & & & 0 & 1 & 2 & 3 & 4 & & \\
\hline \multicolumn{11}{|l|}{ Fall (no HPS) } \\
\hline Control (CK) & 28.8 & 4.3 & 262 & 103.4 & 104.2 & 108.8 & 116.5 & 130.4 & 26.2 & 11.4 \\
\hline R lighting & 26.1 & 3.9 & 224 & 93.2 & 93.3 & 96.9 & 102.8 & 113.2 & 20.1 & 17.0 \\
\hline FR lighting & 29.8 & 4.5 & 293 & 100.5 & 98.4 & 103.8 & 112.4 & 122.5 & 21.2 & 11.3 \\
\hline \multicolumn{11}{|c|}{ Single degree of freedom contrast } \\
\hline CK vs. other & NS & NS & NS & $* *$ & $* *$ & $* *$ & $* *$ & $* *$ & NS & NS \\
\hline R vs. FR & $* *$ & $* *$ & $* *$ & $* *$ & $*$ & $*$ & $*$ & NS & NS & $*$ \\
\hline \multicolumn{11}{|l|}{ Winter (HPS) } \\
\hline Control (CK) & 30.5 & 4.6 & 341 & 95.9 & 95.8 & 96.7 & 99.4 & 105.7 & 8.5 & 9.1 \\
\hline R lighting & 31.0 & 4.3 & 314 & 95.4 & 94.2 & 95.3 & 97.5 & 102.1 & 6.0 & 12.2 \\
\hline FR lighting & 31.5 & 4.3 & 316 & 96.9 & 96.6 & 97.3 & 100.2 & 105.1 & 7.0 & 9.7 \\
\hline \multicolumn{11}{|c|}{ Single degree of freedom contrast } \\
\hline CK vs. other & NS & $*$ & NS & NS & NS & NS & NS & NS & NS & NS \\
\hline R vs. FR & NS & NS & NS & NS & NS & NS & NS & NS & NS & NS \\
\hline \multicolumn{11}{|l|}{ Spring (no HPS) } \\
\hline Control (CK) & 32.0 & --- & 418 & 91.2 & 91.6 & 92.1 & 94.7 & 102.2 & 11.1 & 3.6 \\
\hline R lighting & 33.1 & --- & 472 & 88.9 & 89.1 & 89.3 & 92.3 & 99.4 & 10.5 & 7.1 \\
\hline FR lighting & 33.5 & --- & 505 & 89.1 & 89.7 & 90.2 & 93.8 & 101.7 & 12.5 & 5.4 \\
\hline \multicolumn{11}{|c|}{ Single degree of freedom contrast } \\
\hline CK vs. other & $*$ & --- & $* *$ & $* *$ & $* *$ & $* *$ & $*$ & NS & NS & $* *$ \\
\hline R vs. FR & NS & --- & NS & NS & NS & NS & NS & NS & $*$ & $*$ \\
\hline
\end{tabular}

${ }^{\mathrm{z}}$ Grey level measured by video imaging with a 550-nm filter $(0=$ absolute black; and $255=$ absolute white). Low grey level indicates dark green. ${ }^{\mathrm{y}}$ Shelf life during storage at $13{ }^{\circ} \mathrm{C}$ for 2 weeks.

Ns,**** Nonsignificant or significant at $P=0.05$ or 0.01 , respectively. 
Table 4. The relationship between shelf life (days) of a cucumber and its image grey level (GL) at harvest.

\begin{tabular}{ll}
\hline \hline Experiment & Regression \\
\hline Summer shading & Shelf life $=60.51-0.58(\mathrm{GL})^{\mathrm{z}}, R^{2}=0.434, \mathrm{n}=147$ \\
Summer color filter & Shelf life $=24.43-0.19(\mathrm{GL}), R^{2}=0.465, \mathrm{n}=150$ \\
Fall & Shelf life $=68.27-0.55(\mathrm{GL}), R^{2}=0.442, \mathrm{n}=27$ \\
Winter & Shelf life $=105.19-0.98(\mathrm{GL}), R^{2}=0.551, \mathrm{n}=107$ \\
Spring & Shelf life $=30.49-0.28(\mathrm{GL}), R^{2}=0.102, \mathrm{n}=137$ \\
\hline
\end{tabular}

${ }^{\mathrm{z}}$ Grey level measured by video imaging with a 550-nm filter $(0=$ absolute black; and $255=$ absolute white). Low grey level indicates dark green cucumber.

reports that $\mathrm{R}$ light results in high accumulation of chlorophyll (McLaren et al., 1978), and FR light results in low chlorophyll (Casal et al., 1987; Casal and Aphalo, 1989). This R-enhanced chlorophyll content was observed under low natural daylight conditions in the fall (Table 1). In winter spectral lighting, there was no difference in chlorophyll content and shelf life between $\mathrm{R}$ and FR lighting (Table 3). The ineffectiveness of the $\mathrm{R}$ lighting in the third experiment could have been due to the fact that HPS lighting was used in the winter in all three treatments including control. HPS itself has a high ratio of R/FR, and spectral R lighting contributed little to further increase the R/FR ratio. In the spring spectral lighting experiment, R- and FR-lighted fruit had similar chlorophyll content, but R-lighted fruit had longer shelf lives than FR-lighted fruit (Table 3). This could have been attributed to slow degradation of R-lighted fruit during the third and fourth week in storage. The R-related delay in chlorophyll loss has been observed in detached barley leaves (Biswal and Sharma, 1976), attached mustard leaves (Biswal et al., 1982), and rice leaf segment (Okada et al., 1992). The spring experiment was conducted when the natural daylight was highest among the three lighting experiments. Therefore, it is very likely that $\mathrm{R}$ lighting promotes chlorophyll formation under low light conditions (i.e., fall production) and becomes ineffective when the light intensity is adequate (i.e., spring production). The exact relationship between light intensity and $\mathrm{R} / \mathrm{FR}$ ratio was not possible to determine in the present experiments. However, this relationship has practical implications in commercial greenhouse production in the northern latitudes: whether to use intensity lighting or to use spectral lighting to improve fruit color and shelf life of greenhouse cucumbers.

Canopy light. Chlorophyll content in cucumber peel is related to canopy light intensity and its R/FR ratio reaching the fruit surface as discussed above. These relationships support our previous suggestion that an open canopy is essential for improved shelf life (Klieber et al., 1993). Light intensity decreases from the upper canopy toward the ground (Okada et al., 1992). Low light is associated with low chlorophyll content (Miller and Zalik, 1965). Severe shading causes a decrease in chlorophyll content in some sun plants compared to shade plants (Di Benedetto, 1991). In addition, $\mathrm{R} / \mathrm{FR}$ ratio has been shown to decrease in a crowded plant canopy (Kasperbauer, 1971 and 1987), and such a low R/FR ratio was also associated with low chlorophyll content (Mclaren and Smith, 1978). Sunlight reflected or transmitted from green vegetation is lower in photon flux and lower in R/FR ratio than direct sunlight (Holmes, 1983). In a plant canopy, the R/FR ratio can be as low as 0.1 (Di Benedetto, 1991). This explains the need for an open canopy in greenhouse cucumber production (Klieber et al., 1993). Red light suppressed chlorophyll degradation in leaves (Biswal and Sharma, 1976; Biswal et al., 1982; Okada et al., 1992; Tucker, 1981). This was observed only in our spring spectral lighting experiment. The suppressive effect of light intensity on chlorophyll degradation was negligible in our present experiments (summer shading experiment). In most of our present experiments, chlorophyll content after storage was proportional to that at harvest. The greener the cucumbers are at harvest, the longer their shelf lives are. This was previously suggested (Lin and Ehret, 1991), and now it can be confirmed by using filters and by spectral lighting (Table 4).

Fruit growth. The relationship between fast fruit growth and long shelf life was observed only in one of four experiments in the present study. In the shading experiment, rapid fruit growth was directly related to high light intensity (Table 2). These findings were similar to previous observations that fast-growing fruit had longer shelf lives (Kanellis et al., 1986; Lin and Ehret, 1991). However, this relationship was not observed in other experiments in this study. In the color filter experiment, $\mathrm{R}$ and FR filters transmitted only $10 \%$ light. Such low light intensity reduced fruit diameter, but it did not affect fruit length and fruit weight (Table 2). Both R- and FR-lighted fruit had zero shelf life. In the fall spectral lighting experiment (Table 3), R-lighted fruit were smaller but had longer shelf lives than FR-lighted ones. In the winter spectral lighting experiment, there was no difference between $\mathrm{R}$ and FR lighting in fruit growth and shelf life. In the spring spectral lighting experiment, there was no difference between $\mathrm{R}$ and FR lighting in fruit growth, but R-lighted fruit had longer shelf lives than the FR-lighted ones. The relationship between fruit growth and shelf life became complicated in the present experiments. Our previous observation also indicated that fast fruit growth is not always associated with long shelf life in the experiments where leaf-to-fruit ratio was studied (Klieber et al., 1993). The exact relationship between rate of fruit growth and shelf life needs further study.

In summary, shelf life of a long English cucumber is influenced by incident canopy light. Cucumber fruit developing under high light intensity in the canopy have high chlorophyll content at harvest, and these fruit have longer shelf lives because the rate of chlorophyll degradation is the same among treatments. The role of $\mathrm{R}$ lighting appears to be secondary since $\mathrm{R}$ lighting was effective in promoting chlorophyll formation only under low light conditions (e.g., fall experiment), but not effective when light intensity is high enough (e.g., spring experiment). This evidence is further supported by the winter experiment, where HPS lighting was used, and no difference between R and FR lighting was detected. The data obtained from the present study provided direct evidence to support our previous hypothesis that an open canopy would improve fruit color and shelf life of greenhouse grown cucumbers possibly through high chlorophyll content in the peel as a result of high light intensity and, under low light conditions, high R/FR ratio.

\section{Literature Cited}

Barreiro, R., J.J. Guiamet, J. Beltrano, and E.R. Montaldi. 1992. Regulation of the photosynthetic capacity of primary bean leaves by the red : far-red ratio and photosynthetic photon flux density of incident light. Physiol. Plant. 85:97-101.

Biswal, U.C. and R. Sharma. 1976. Phytochrome regulation of senescence in detached barley leaves. Z. Pflanzenphysiol. Bd. 80S:71-73.

Biswal, U.C., H. Kasemir, and H. Mohr. 1982. Phytochrome control of degreening of attached cotyledons and primary leaves of mustard (Sinapis alba L.) seedlings. Photochem. Photobiol. 35:237-241.

Bjorkman, O. 1981. Responses to different quantum flux densities, p. 57107. In: O.L. Lange, P.S. Nobel, C.B. Osmond, and H. Ziegler (eds.). 
Encyclopedia of plant physiology. n.s. vol. XIIA, Physiological plant ecology. Springer Verlag, Berlin.

British Columbia Ministry of Agriculture and Fisheries. 1988. Nursery, greenhouse vegetable and ornamental 1988/89 production guide for commercial growers. British Columbia Ministry Agri Fisheries, Victoria, B.C.

Casal, J.J., P.J. Aphalo, and R.A. Sanchez. 1987. Phytochrome effects on leaf growth and chlorophyll content in Petunia axilaris. Plant Cell Environ. 10:509-514.

Casal, J.J. and P.J. Aphalo. 1989. Phytochrome control of chlorophyll content in mature attached leaves of Petunia axilaris. Annals of Botany 63:595-598.

Di Benedetto, A.H. 1991. Light environment effects on chlorophyll content in Aglaonema commutatum. J. Hort. Sci. 66:283-289.

Holmes, M.G. 1983. Spectral distribution of radiation within plant canopies, p. 147-158. In: H. Smith (ed.). Plants and daylight spectrum. Academic Press, London.

Kanellis, A.K., L.L. Morris, and M.E. Saltveit. 1986. Effect of stage of development in postharvest behavior of cucumber fruit. HortScience 21:1165-1167.

Kasperbauer, M.J. 1971. Spectral distribution of light in a tobacco canopy and effects of end-of-day light quality on growth and development. Plant Physiol. 47:775-778.
Kasperbauer, M.J. 1987. Far-red light reflection from green leaves and effects on phytochrome-mediated assimilate partitioning under field conditions. Plant Physiol. 85:350-354.

Klieber, A., W.C. Lin, P.A. Jolliffe, and J.W. Hall. 1993. Training methods affect canopy light exposure and shelf life of long English cucumber. J. Amer. Soc. Hort. Sci. 118:786-790.

Lin, W.C. 1989. Cucumber yellowing-A challenge for quality. Proc. 5th Intl. Controlled Atmosphere Conf., Wenatchee, Wash. 2:126-133.

Lin, W.C. and D.L. Ehret. 1991. Nutrient concentration and fruit thinning affect shelf life of long English cucumber. HortScience 26:1299-1300.

Lin, W.C., J.W. Hall, and A. Klieber. 1993. Video imaging for quantifying cucumber fruit color. HortTechnology 3:436-439.

Mclaren, J.S. and H. Smith. 1978. Phytochrome control of the growth and development of Rumex obtusifolius under simulated canopy light environments. Plant Cell Environ. 1:61-67.

Miller, R.A. and S. Zalik. 1965. Effect of light quality, light intensity and temperature on pigment accumulation in barley seedlings. Plant Physiol. 40:569-574.

Okada, K., Y. Inoue, K. Satoh, and S. Katoh. 1992. Effects of light on degradation of chlorophyll and proteins during senescence of detached rice leaves. Plant Cell Physiol. 33:1183-1191.

Tucker, D.J. 1981. Phytochrome regulation of leaf senescence in cucumber and tomato. Plant Sci. Lett. 23:103-108. 